\title{
In vitro Antioxidant Property and Acute Toxicity Study of Methanol Extract of Leaves of Zingiber officinale and Curcuma longa
}

\author{
Osebhahiemen Ibukun*, Eniola Esther Oluwadare
}

\section{Osebhahiemen Ibukun*, Eniola Esther Oluwadare}

Department of Biochemistry, Faculty of Basic Medical Sciences, University of Medical Sciences, Ondo, NIGERIA.

Correspondence

Dr. Osebhahiemen Ibukun

Department of Biochemistry, Faculty of Basic Medical Sciences, University of Medical Sciences, P.O. Box 536, Ondo, NIGERIA.

E-mail: oojemekele@unimed.edu.ng

History

- Submission Date: 08-08-2021;

- Review completed: 07-09-2021;

- Accepted Date: 21-10-2021.

DOI : 10.5530/fra.2021.2.10

Article Available online

http://www.antiox.org

\section{Copyright}

(C) 2021 Phcog.Net. This is an openaccess article distributed under the terms of the Creative Commons Attribution 4.0 International license.

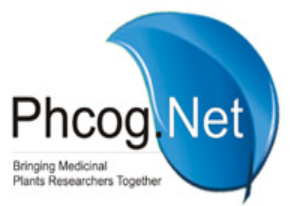

\begin{abstract}
Background: Zingiber officinale (ginger) and Curcuma longa (turmeric) are perennial herbs grown in tropical and sub- tropical regions. Both plants have unique aroma and are used for the treatment of various diseases. Their roots have been extensively studied by other researchers. Therefore, this current study focused on the leaves rather than roots, evaluating the phytochemical constituents, in vitro antioxidant activity and acute toxicity. Methods: Screening of phytochemicals and in vitro antioxidant activity were carried out spectrophotometrically using standard protocols. Acute toxicity testing was done by administering (orally) varying concentrations (100-2000mg/kg body weight) of extracts to Wistar rats weighing 120-140 (grams) Results: Flavonoids, tannins, phenolic compounds, saponinis, glycosides and steroids were qualitatively detected in both extracts. Quantitatively, methanol extract of leaves of Zingiber officinale had significantly higher $(p<0.05)$ concentrations of total phenol, total flavonoids, total tannins, total proanthocyanidins, total hydroxy cinnamic acids, ferric reducing antioxidant power (FRAP), total antioxidant capacity, 1,1-diphenyl-2-picrylhydrazyl (DPPH) radical scavenging activity than extract of Curcuma longa. Furthermore, there was no physical sign of intoxication or mortality in rats that were administered the extracts. Conclusion: Leaves of Zingiber officinale and Curcuma longa may be good sources of safe phytochemicals and antioxidants that would be useful in the food and pharmaceutical sectors.

Key words: Ginger, Turmeric, Phytochemicals, Antioxidants, Toxicity, Leaves.
\end{abstract}

\section{INTRODUCTION}

Phytochemicals are natural components of plants usually classified as secondary metabolites. They are of numerous benefits to the well-being of humans. These phytochemicals are present in different parts of plant and are used by humans for healing of diseases. Phytochemicals found in medicinal plants include saponins, alkaloids, flavonoids, lycopenes, anthocyanins, tannins, alpha and beta carotene, Lutein, Zeaxanthin, Glucosinolates, e.t.c. ${ }^{1}$

Antioxidants include chemical compounds with ability to defend human cells against oxidative stress and quench damaging effects of free radicals. ${ }^{2}$ Antioxidants can be found in most fruits and vegetables and they play an important role in the maintenance of health and prevention of diseases. Culinary herbs and medicinal herbs contain high levels of antioxidants. Zingiber officinale (ginger) and Curcuma longa (tumeric) belong to the same family of Zingiberaceae and are commonly used as spices in cooking. They have been utilized in treating cancer, inflammation, microbial infections, diabetes, arthritis, anorexia, cough, hepatic disorders and sinusitis. ${ }^{3}$ Most researches on Zingiber officinale and Curcuma longa have been on the roots rather than the leaves. Furthermore, to the best of our knowledge, there has been no documented research on the phytochemistry, acute toxicity study and antioxidant property of the leaves of Zingiber officinale and Curcuma longa. Therefore, this study sets out to evaluate the phytochemical constituents, antioxidant property (in vitro) as well as acute toxicity of methanol extract of leaves of Zingiber officinale and Curcuma longa.

\section{MATERIALS AND METHODS}

\section{Chemicals}

Sulphuric acid, Folin-Ciocalteau reagent, gallic acid, vanillin, chlorogenic acid, sodium phosphate, ferric chloride, sodium carbonate, aluminium chloride, quercetin, ascorbic acid, tannic acid, Iron II sulphate, Hydrochloric acid, DPPH, methanol, glacial acetic acid, 2,4,6-tripyridylstriazine (TPTZ), Potassium iodide, Ammonium molybdate, Iodine, lead acetate, sodium nitrate were obtained from Sigma Chemical Company, U.S.A.

\section{Animals}

Thirty three male Wistar rats weighing (120-140) g were obtained from University of Medical Sciences (UNIMED), Ondo. Ethical approval for the use of experimental animals was also obtained from Ethical clearance committee of UNIMED.

Cite this article: Ibukun O, Oluwadare EE. In vitro Antioxidant Property and Acute Toxicity Study of Methanol Extract of Leaves of Zingiber officinale and Curcuma longa. Free Radicals and Antioxidants. 2021;11(2):42-5. 


\section{Plant materials}

Fresh leaves of Zingiber officinale and Curcuma longa were collected from a private farm in Ibadan, Oyo State, Nigeria. The fresh leaves were identified by a botanist at University of Benin, Edo State, Nigeria. Herbarium specimen with voucher numbers UBHz 368 and UBHc 253 were deposited at the Herbarium for Zingiber officinale and Curcuma longa, respectively.

\section{Preparation of plant extracts}

The leaves of Zingiber officinale and Curcuma longa were rinsed properly with water and air dried. The dried leaves were pulverized, followed by soaking individually in methanol for $72 \mathrm{hr}$ and filtering with a muslin fabric. It was thereafter concentrated using rotary evaporator at $60^{\circ} \mathrm{C}{ }^{4}$

For the analysis, each extract was dissolved in methanol $(1 \mathrm{mg} / \mathrm{mL})$ and were utilized as triplicates.

\section{Qualitative phytochemical screening}

Alkaloids, tannins, terpenoids, saponins, flavonoids, glycosides, steroids and phenolic compounds were screened qualitatively using the standard procedures described by Sofowora, $1982 .^{5}$

\section{Quantitative phytochemical screening Determination of total phenols}

Distilled water $(4.5 \mathrm{~mL})$ was added to $0.5 \mathrm{~mL}$ of gallic acid standard or extract. Thereafter, $2.5 \mathrm{~mL}$ of Folin- Ciocalteau reagent (10\%) was added. Two millilitres of $\mathrm{Na}_{2} \mathrm{CO}_{3}$ was then added to the mixture and incubated for thirty minutes $\left(25^{\circ} \mathrm{C}\right)$, absorbance was then measured $(760 \mathrm{~nm}){ }^{6}$

\section{Determination of total flavonoids}

One $\mathrm{mL}$ of Aluminium chloride $(2 \%)$ in ethanol was mixed with $1 \mathrm{~mL}$ of quercetin standard or extract followed by incubation at $25^{\circ} \mathrm{C}$ for one hour. Absorbance was measured at $420 \mathrm{~nm}^{7}$

\section{Determination of total tannins}

Distilled water $(6.5 \mathrm{~mL})$ was added to $1 \mathrm{~mL}$ of the extract or tannic acid standard. Thereafter, $0.5 \mathrm{~mL}$ of Folin-Denis reagent, $1 \mathrm{~mL}$ of sodium carbonate $(7 \%)$ and $1 \mathrm{~mL}$ of distilled water were added. Absorbance was determined at $700 \mathrm{~nm}$ within 3 min. $^{8}$

\section{Determination of total proanthocyanidins}

To $0.5 \mathrm{ml}$ of extract or standard ascorbic acid solution was added $1 \mathrm{ml}$ of $4 \%$ vanillium methanol solution (v/v) and $0.75 \mathrm{~mL}$ of concentrated hydrochloric acid was added. The solution was left undisturbed for $15 \mathrm{~min}$. Thereafter, absorbance was determined at 500 $\mathrm{nm}^{9}$

\section{Determination of total hydroxycinnamic acids}

Extract or chlorogenic acid standard (0.5 millilitres) was mixed with $0.5 \mathrm{M} \mathrm{HCl}(1 \mathrm{~mL})$, Arnow reagent $(1 \mathrm{~mL}), 2.125 \mathrm{M} \mathrm{NaOH}(1 \mathrm{~mL})$ and distilled water $(1.5 \mathrm{~mL})$. It was then mixed thoroughly and absorbance was measured $(525 \mathrm{~nm}) .^{10}$

\section{In vitro antioxidant activity}

\section{1, 1-diphenyl-2-picryl-hydrazyl (DPPH) radical scavenging activity}

Briefly, $0.5 \mathrm{~mL}$ of $0.3 \mathrm{mM}$ DPPH prepared in methanol was added to $2 \mathrm{~mL}$ of various concentrations $(10-200 \mu \mathrm{g} / \mathrm{ml})$ of the extract or ascorbic acid (positive control). The solution was mixed thoroughly and incubated for $15 \mathrm{~min}$ at $25^{\circ} \mathrm{C}$ away from light, absorbance was measured $(517 \mathrm{~nm}) .{ }^{11}$

\section{Ferric reducing antioxidant power}

To $1.5 \mathrm{~mL}$ of freshly prepared reagent solution (a mixture of $100 \mathrm{~mL}$ of acetate buffer, $10 \mathrm{~mL}$ of TPTZ solution, $10 \mathrm{~mL}$ of Ferric chloride solution, $12 \mathrm{~mL}$ of distilled water) was added to $1 \mathrm{~mL}$ of the extract or ascorbic acid (positive control) or Iron II sulphate (standard). This was followed by incubation at $37^{\circ} \mathrm{C}$ for $30 \mathrm{~min}$. Absorbance was measured at $593 \mathrm{~nm} .{ }^{12}$

\section{Total Antioxidant Capacity}

Briefly, $1 \mathrm{~mL}$ of extract or trolox standard was mixed with phosphomolybdenum reagent $(2.7 \mathrm{~mL})$ followed by Incubation for ninety minutes (temperature of $95^{\circ} \mathrm{C}$ ). The mixture was cooled to room temperature and absorbance was measured spectrophotomerically at $695 \mathrm{~nm} \cdot{ }^{13}$

\section{Acute toxicity study}

Acute toxicity test was carried out on the extracts according to method of OECD, 2008. ${ }^{14}$

A total of eleven groups with three rats (Wistar strain) weighing between $(120$ - 140) g per group were utilized. Ten groups were orally administered $1 \mathrm{~mL}$ of varying doses $(100,250,500,1000$ and 2000) $\mathrm{mg} / \mathrm{kg}$ of the extract (Zingiber officinale or Curcuma longa) dissolved in the distilled water while the eleventh group (control) received $1 \mathrm{~mL}$ of distilled water only. After the administration, animals were observed closely for physical signs of toxicity and mortality for two weeks. All animals were provided with water and food during the study.

\section{Statistical analysis}

The experimental results were expressed as mean \pm standard error of mean (SEM) of three replicates and were subjected to student's t-test. Where applicable, one-way analysis of variance (anova) followed by Turkey's test (rather than $t$ test) was used for inter-group comparison of data and $p$ values $<0.05$ were considered significant.

\section{RESULTS}

\section{Phytochemical composition}

The presence of flavonoids, tannins, phenolic compounds, saponinis, glycosides and steroids were qualitatively confirmed in both extracts. However, alkaloids were below detectable levels in the extracts.

Total phenol, total flavonoids, total tannins, total proanthocyanidins and total hydroxycinnamic acids concentration of methanol extract of leaves of Zingiber officinale was significantly higher $(p<0.05)$ than that of Curcuma longa.

\section{In vitro antioxidant activity of methanol extract of leaves} of Zingiber officinale and Curcuma longa

Result revealed that methanol extract of Zingiber officinale had a significantly higher $(p<0.05)$ FRAP, DPPH radical scavenging activity and total antioxidant capacity than methanol extract of Curcuma longa.

\section{Result of Acute toxicity study of methanol extract of leaves of Zingiber officinale and Curcuma longa}

There was no physical sign of intoxication in all rats that were administered $100-2000 \mathrm{mg} / \mathrm{kg}$ body weight of extracts of Zingiber officinale or Curcuma longa. No mortality was recorded in these groups during the two weeks period of study.

\section{DISCUSSION}

The study of phytochemicals, free radicals and antioxidants is important in medicine due to their implications in different disease conditions. Antioxidants are substances that inhibit oxidation and are capable of 
counteracting the damaging effects of oxidation in body tissues. They create a barrier from free radical damage that results in delaying process of oxidation. ${ }^{15}$ This present study evaluated the phytochemical constituents, in vitro antioxidant property and acute toxicity of methanol extract of leaves of Zingiber officinale and Curcuma longa. The qualitative phytochemical screening showed the presence of flavonoids, tannins, phenolic compounds, saponinis, glycosides and steroids in both extracts. However, alkaloids were below detectable levels in the extracts (Table 3.1). In quantitative terms, methanol extract of leaves of Zingiber officinale has a significantly higher $(p<0.05)$ concentration of total phenol, total flavonoids, total tannins, total proanthocyanidins and total hydroxycinnamic acids than that of Curcuma longa (Table 3.2).

The FRAP assay utilizes antioxidants to reduce Ferric $\left(\mathrm{Fe}^{3+}\right)$ ion to ferrous $\left(\mathrm{Fe}^{2+}\right)$ ion. ${ }^{16}$ In this study, methanol extract of leaves of Zingiber officinale had a significantly higher $(p<0.05)$ FRAP value than extract of Curcuma longa, but was significantly lower $(p<0.05)$ than that of ascorbic acid standard (Figure 3.1). The principle of DPPH antioxidant assay lies on the ability of a potential antioxidant to scavenge the stable radical of $\mathrm{DPPH}$. In the presence of antioxidants, DPPH can accept an electron

Table 3.1: Qualitative phytochemical constituents of methanol extracts of leaves of Zingiber officinale and Curcuma longa.

$\begin{array}{ccc}\text { Phytochemical } & \text { Zingiber officinale } & \text { Curcuma longa } \\ \text { Alkaloids } & - & - \\ \text { Saponins } & + & + \\ \text { Tannins } & ++ & ++ \\ \text { Terpenoids } & + & + \\ \text { Phenolic compounds } & ++ & + \\ \text { Flavonoids } & +++ & +++ \\ \text { Glycosides } & +++ & ++ \\ \text { Steroids } & + & +\end{array}$

KEY: - = Absent; + = Trace amount; ++ = moderate amount; +++ = High amount

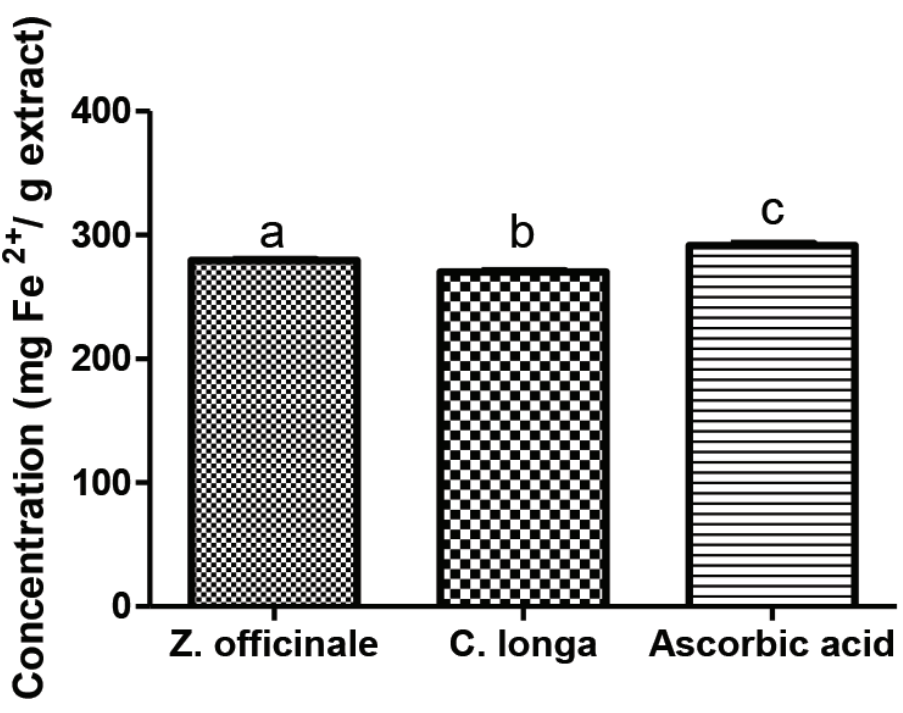

Figure 3.1: Ferric reducing antioxidant power of methanol extract of leaves of Zingiber officinale and Curcuma longa.

Values are expressed as mean \pm SEM ( $n=3 /$ group). Different alphabets a, b, c on different bars show that values for Zingiber officinale, Curcuma longa and ascorbic acid are significantly different from each other at $p<0.05$. or a hydrogen atom from the antioxidant scavenger molecule, to be converted to a more stable DPPH molecule. ${ }^{16}$ The methanol extract of Zingiber officinale was a better scavenger of DPPH radical than extract of Curcuma longa (Figure 3.2). It had a lower $\mathrm{IC}_{50}$ (concentration that will scavenge $50 \%$ of DPPH radical) than extract of Curcuma longa. .The lower the $\mathrm{IC}_{50}$ value, the more the radical scavenging power of an antioxidant. However, ascorbic acid had a lower $\mathrm{IC}_{50}$ than both extracts, hence it was a more potent scavenger of $\mathrm{DPPH}$ radical than the plant extracts (Table 3.3).

Total antioxidant assay (TAC) was done using phosphomolybdenum assay. It estimates the extent to which an antioxidant reduces Mo (VI) to Mo (V). It gives a direct estimation of reducing capacity of antioxidant. ${ }^{17}$ In this study, methanol extract of leaves of Zingiber officinale had significantly higher $(p<0.05)$ total antioxidant capacity than extract of Curcuma longa (Figure 3.3). Antioxidant capacity of plants has been suggested to

Table 3.2: Quantitative phytochemical constituents of methanol extracts of leaves of Zingiber officinale and Curcuma longa.

\begin{tabular}{|c|c|c|}
\hline Phytochemical & Zingiber officinale & Curcuma longa \\
\hline $\begin{array}{c}\text { Total phenols } \\
\text { (mg gallic acid equivalent/g extract) }\end{array}$ & a $723.00 \pm 20.02$ & b $575.00 \pm 10.05$ \\
\hline $\begin{array}{c}\text { Total flavonoids } \\
\text { (mg quercetin equivalent/g extract) }\end{array}$ & a $105.80 \pm 1.50$ & b $84.00 \pm 1.35$ \\
\hline $\begin{array}{c}\text { Total tannins } \\
\text { (mg tannic acid equivalent } / g \\
\text { extract) }\end{array}$ & a $187.50 \pm 2.50$ & b $48.00 \pm 1.50$ \\
\hline $\begin{array}{l}\text { Total proanthocyanidins } \\
\text { (mg ascorbic acid equivalent } / g \\
\text { extract) }\end{array}$ & a $30.04 \pm 1.00$ & b $20.26 \pm 1.25$ \\
\hline $\begin{array}{c}\text { Total hydroxycinnamic acids } \\
\text { (mg chlorogenic acid equivalent/g } \\
\text { extract) }\end{array}$ & a $88.14 \pm 2.00$ & b $26.58 \pm 0.05$ \\
\hline
\end{tabular}

Values are expressed as mean \pm SEM ( $n=3$ /group). Different alphabets $a, b$ on same row show that value for Zingiber officinale is significantly different from that of Curcuma longa at $p<0.05$.

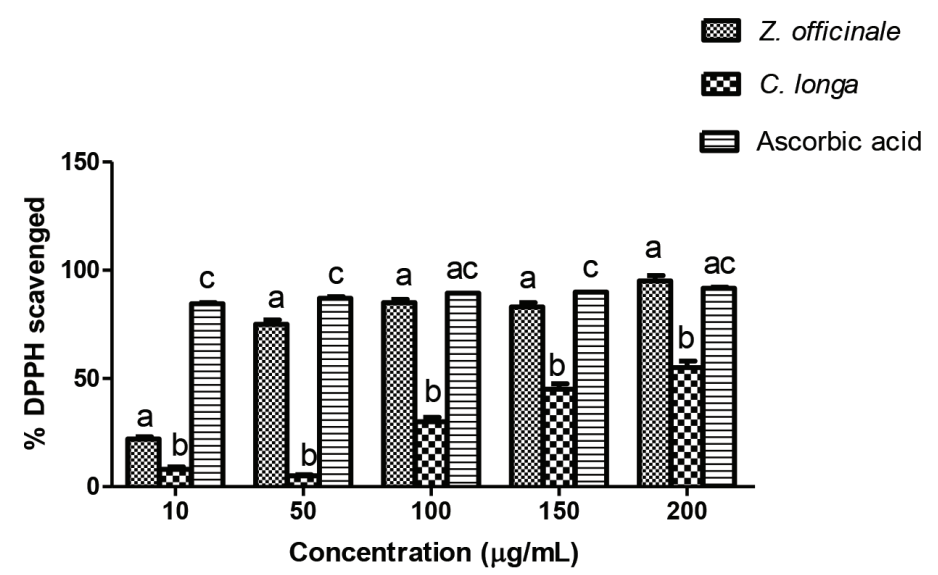

Figure 3.2: DPPH radical scavenging activity of methanol extract of leaves of Zingiber officinale and Curcuma longa.

Values are expressed as mean \pm SEM ( $n=3$ /group). Different alphabets on grouped bars show that values for Zingiber officinale, Curcuma longa and ascorbic acid are significantly different from each other at $p<0.05$. 
Table 3.3: DPPH IC ${ }_{50}$ values of methanol extract of leaves of Zingiber officinale and Curcuma longa.

$\begin{array}{cc}\text { Extract } & \mathrm{IC}_{50} \text { values }(\mu \mathrm{g} / \mathrm{ml}) \\ \text { Zingiber officinale } & { }^{\mathrm{a}} 32.169 \pm 0.64 \\ \text { Curcuma longa } & \mathrm{b} 186.1 \pm 25.80 \\ \text { Ascorbic acid } & { }^{\mathrm{c}} 5.905 \pm 0.005\end{array}$

Values are expressed as mean \pm SEM ( $n=3$ /group). Different alphabets $a, b, c$ on values show that values for Zingiber officinale, Curcuma longa and ascorbic acid are significantly different from each other at $p<0.05$.

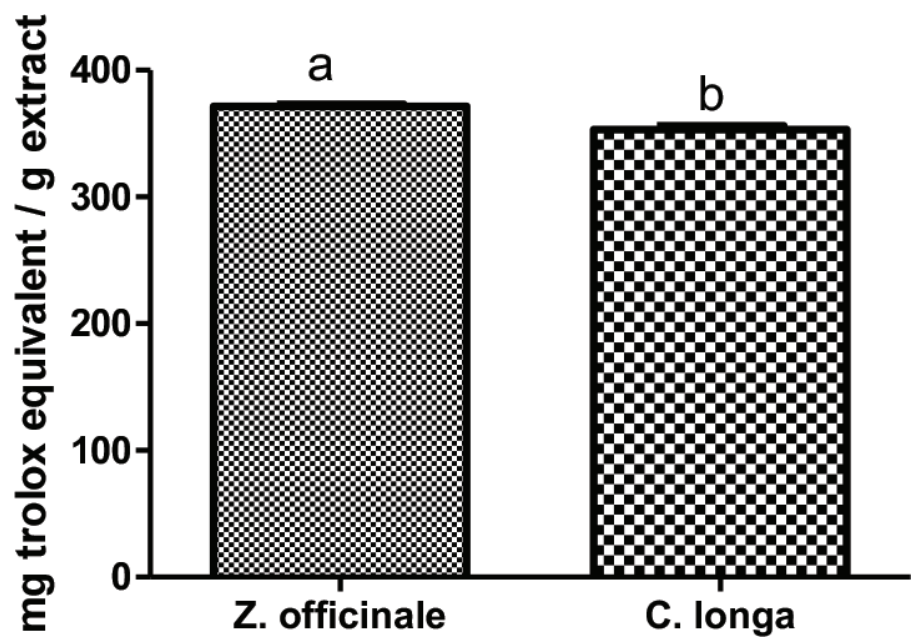

Figure 3.3: Total antioxidant capacity of methanol extract of leaves of Zingiber officinale and Curcuma longa.

Values are expressed as mean \pm SEM ( $n=3$ /group). Different alphabets $\mathrm{a}$, $\mathrm{b}$ on different bars show that value for Zingiber officinale is significantly different from that of Curcuma longa at $p<0.05$.

be a combination of the roles played by the different groups of phytochemicals, rather than any one group. ${ }^{18}$ Therefore, the higher the concentration of phytochemicals in a compound, the higher the antioxidant activity. The results obtained from this research showed that leaves of Zingiber officinale contained higher amount of phytochemicals, consequently, it was a more powerful antioxidant than leaves of Curcuma longa.

Acute toxicity study showed that there was no physical sign of toxicity in all groups of Wistar rats that received either methanol extract of leaves of Zingiber officinale or Curcuma longa. Furthermore, there was no mortality in all groups.

\section{CONCLUSION}

This study revealed that methanol extract of leaves of Curcuma longa and Zingiber officinale were safe, had high amount of phytochemicals and antioxidant capacity. However, further research is needed to isolate and characterize the active compounds from these leaves, as this would be vital in discovery of safe and affordable drugs.

\section{ACKNOWLEDGEMENT}

The authors are grateful to Mrs M.O. Adeleke and Mrs M.A. Adewole of laboratory unit (Department of Biochemistry), University of Medical Sciences, Ondo, Nigeria.

\section{CONFLICT OF INTEREST}

The authors declare no conflict of interest.

\section{REFERENCES}

1. Zhang YJ, Gan RY, Li S, Zhou Y, Li AN, Xu DP, Li HB. Antioxidant phytochemicals for the prevention and treatment of chronic diseases. Molecules. 2015;20(12):21138-56. doi: 10.3390/molecules201219753, PMID 26633317.

2. Kampa M, Castanas E. Human health effects of air pollution. Environ Pollut. 2008;151(2):362-7. doi: 10.1016/j.envpol.2007.06.012. PMID 17646040.

3. Pulliah T. Encyclopedia of world medicinal plants. Vol. 4. New Delhi, India: Regency Publication; 2006.

4. Gayasuddin MD, Parvez MD, Mohd I, Venkataiah G. Effect of ethanolic extract of Piper nigrum L. fruits on midazolam induced hypnosis in rats. IJPT. 2013;3(1):5-8.

5. Sofowora A. Screening plants for bioactive agents. In: Medicinal plants and traditional medicine in Africa. Ibadan: Spectrum Books Ltd; 1993. p. 128-61.

6. Cicco N, Lanorte MT, Paraggio M, Viggiano M, Lattanzio V. A reproducible, rapid and inexpensive Folin-Ciocalteu micro-method in determining phenolics of plant methanol extracts. Microchem J. 2009;91(1):107-10. doi: 10.1016/j.microc. 2008.08.011.

7. Miliauskas G, Venskutonis PR, van Beek TA. Screening of radical scavenging activity of some medicinal and aromatic plant extracts. Food Chem. 2004;85(2):231-7. doi: 10.1016/j.foodchem.2003.05.007.

8. Ganjiwale R, Wadher S, Yeole P, Polshettiwar S. Spectrophotometric estimation of total tannins in some ayurvedic eye drops. Indian J Pharm Sci. 2007;69(4):574-6. doi: 10.4103/0250-474X.36949.

9. Sun B, Ricardo-da-Silva JM, Spranger I. Critical factors of vanillin assay for catechins and proanthocyanidins. J Agric Food Chem. 1998;46(10):4267-74 doi: 10.1021/jf980366j.

10. St-Pierre F, Achim A, Stevanovic T. Composition of ethanolic extracts of wood and bark from Acer saccharum and Betula alleghaniensis trees of different vigor classes. Ind Crops Prod. 2013;41:179-87. doi: 10.1016/j.indcrop.2012.04.027.

11. Brand-Williams W, Cuvelier ME, Berset C. Use of a free radical method to evaluate antioxidant activity. LWT - Food Science and Technology. 1995;28(1):25-30. doi: 10.1016/S0023-6438(95)80008-5.

12. Benzie IF, Strain JJ. The ferric reducing ability of plasma (FRAP) as a measure of "antioxidant power": the FRAP assay. Anal Biochem. 1996;239(1):70-6. doi: 10.1006/abio.1996.0292, PMID 8660627.

13. Prieto $P$, Pineda $M$, Aguilar M. Spectrophotometric quantitation of antioxidant capacity through the formation of a phosphomolybdenum complex: specific application to the determination of vitamin E. Anal Biochem. 1999;269(2):337-41. doi: 10.1006/abio.1999.4019, PMID 10222007.

14. OECD. Test No. 407: repeated Dose 28-day Oral Toxicity Study in Rodents. In: OECD guidelines for the testing of chemicals; 2008.

15. Cadenas E, Davies KJ. Mitochondrial free radical generation, oxidative stress, and aging. Free Radic Biol Med. 2000;29(3-4):222-30. doi: 10.1016/s08915849(00)00317-8, PMID 11035250.

16. Jothy SL, Aziz A, Chen Y, Sasidharan S. Antioxidant Activity and Hepatoprotective Potential of Polyalthia longifolia and Cassia spectabilis Leaves against Paracetamol-Induced Liver Injury. Evid Based Complement Alternat Med. 2012;2012:561284. doi: 10.1155/2012/561284, PMID 23243455.

17. Phatak RS, Hendre A. Total antioxidant capacity (TAC) of fresh leaves of Kalanchoe pinnata. J Pharmacogn Phytochem. 2014;2(5):32-5.

18. Akinrinde AS, Afolayan AJM, Bradley G. Phytochemical composition and antioxidant activities of Dianthus thunbergii Hooper and Hypoxis argentea Harv ex Baker: plants used for the management of diabetes mellitus in Eastern Cape, South Africa. Pharmacogn Mag. 2018;14(54):195-202. doi: 10.4103/ pm.pm_157_17, PMID 29720831.

Cite this article: Ibukun O, Oluwadare EE. In vitro Antioxidant Property and Acute Toxicity Study of Methanol Extract of Leaves of Zingiber officinale and Curcuma longa. Free Radicals and Antioxidants. 2021;11(2):42-5. 